\section{CHARING-CROSS HOSPITAL.}

\section{To the Editor of THE Lancet.}

SIR:-I herewith embrace the earliest opportunity of forwarding to you a statement of the proceedings that have lately taken place at the Charing-Cross Hospital. You will, I trust, therein find a most satisfactory refutation of the calumny with which I have unfortunately been assailed, and I doubt not but you will also find abundant matter deserving of your most serious notice. As far as regards myself, I am anxious that the whole of my conduct in the business should appear before the members of my profession and the public, and $I$ shall be glad to afford every opportunity in my power to lay my case before, and to give every explanation I am able, either to the Council of the Royal College of Surgeons (to whom I shall make application on the subject), or to a general meeting of the whole profession. Unless the General Board of Governors can be brought to do justice to my case, I shall feel it necessary to appeal to the laws of my country. Dr. Sigmond has already given notice of action for defamation to the reverend chairman of the special committee. I have the honour to be, Sir, yours very obediently,

T. J. PetTig Rew.

Saville-row, Aug. 27, 1836.

ABSTRACT OF

\section{MR. PETTIGREW'S ADDRESS}

TO THE

\section{GOVERNORS AND SUBSCRIBERS OF THE} CHARING-CROSS HOSPITAL,

On some late proceedings at that Institution.

Mr. Petrigrew addresses the governors and subscribers, to demonstrate to them that " serious consequences must ensue unless the entire direction of the hospital be changed." The institution, he says, has now been two years and a half in operation, "a period sufficiently long to place all its arrangements for the care of patients in proper order." As regards the execution of his own duties in the institution, he says that " he believes it will not be asserted by any one that he has been neglectful of them, either in a professiunal or a humane point of view. If it should be (he adds), I desire only that the governors and subscribers of the hospital will go round the wards and make enquiries of the patients and the nurses. In short, I fear that no little portion of the animosity which has been evinced towards me, has arisen from the expressions of gratitude which it has been my happiness to receive from my patients in the hospital. This, however, is by no means the sole cause. Another will be found in my desire, in com- mon with that of my respected colleague, Dr. Sigmond, to unite the hospital with the School of Medicine at the King's College, by which a vast accession of strength would be derived to the hospital, a considerable increase of its funds produced, a connection of the highest respectability established, and a source of deserved emolument opened to the various professional officers of the institution. But this Dr. Golding, (the director,) feels would take from his hands a portion of that control which he and his friend Mr. Robertson, (the honorary secretary, have so long entirely possessed. The committeebook of the hospital will show that rarely more than three members, often only one attended besides the director and the honorary secretary, and all the measures for the regulation of the institution, its medical school, $\& c$, have originated from those few indi. viduals.

"Now, let us see the manner in which the duties of the director (an officer, be it remembered, not to be found in any other hos. pital of the metropolis, and in this instance filled by one of the medical officers) are per. formed as it respects the patients, and then let the governors and subscribers say whether it is proper that their charity should be dispensed by one so deaf to humanity, and so tyrannous in his conduct. These are heavy accusations, and particularly so to one who has been the chief instrument in erecting the hospital. But the fact is, that that man who, as he proceeds along the wards of the hospital, ought to be greeted by the blessings of the poor, now only receives their execrations and their curses. His manners are revolting. His mode of address is rude, abrupt, and cruel; rarely does a kind word escape his lips; all is harshness and severity. If a patient has been bat a few weeks in the hospital, his anxiety manifests itself to put him out. But the dismissal rests with the professional offcer under whose charge the patient may happen to be, and not with the director; and should the poor creature unfortunately be upon full diet, or his calamity such as to need the daily addition of a little porter, the enquiries repeatedly made to such patients, as to when they are going ont, the length of time they have been in, \&c., are unbounded. I will give an instance. It occurred to a patient of the name of Moffat, admitted under my care for one of the very worst ulcers of the leg I ever saw. This was an exceed. ingly well-behaved man, labouring under great poverty, and thus his disease was greatly aggravated. I took him into the hospital, and attended to his general health, and the improvement of his limb was most extraordinary. It was a matter of great instruction to the pupils, as showing what proper rest and food might do under apparently the most unfavourable circumstances, and a limb was thus saved to the individual. 
I found this man, in the course of my rounds, often very much agitated; and $I$ at length (but not without much urgency) obtained from him an avowal that, upon Dr. Golding visiting the wards, he was always spoken to in such an unkind and harsh manner, as to the length of time he had been there, the time when he was to go out, \&c., that he could not endure it. He even wished me to discharge him; but I represented to him that, as he would speedily be quite recovered, I wished him to remain until that should take place, and that, if Dr. Golding spoke to him again upon the subject, to refer him to me, as the officer having the charge of the case, and to whom, and not to the patient, certainly the application should have been made. Suddenly, however, one night, goaded by Dr. G.'s conduct, the man in a state of distraction quitted the hospital ; and he was seen by one of the house pupils at three o'clock in the morning, wandering about the streets without a place to shelter him, and without a sixpence in his pocket.

"I will cite another case. It is that of a poor German, recommended to the hospital by Mr. Stultz, who generously gave me one hundred guineas for the institution. This was a very intelligent and well-conducted man, and of most quiet manners. He had a disease of the hip-joint, for which caustic issues were necessary, and a long confinement to bed. At length he was sufficiently recovered to walk, and I got him into the Sea-Bathing Infirmary. At his departure, he left the following letter for me, and another, but of greater severity of expression, for Dr. Sigmond, who had attended the case with me:-

" 'Charing-Cross Hospital, 13 th July, 1836.

" 'SIR :-I return you my sincere and grateful thanks for the very great kindness and humanity $I$ received from you while under your care, and for the interest you felt for my admission into the Margate Infirmary. I feel your kindness the more when I consider the harsh behaviour of Dr. Golding, who ought to have treated me with more kindness, according to the general hospitality of this country, when he considered I was an afficted foreigner, and a friendless stranger in London. I am, Sir, your most obedient humble servant,

$$
\text { " ' George Swemmer. }
$$

\section{" 'Mr. Pettigrew.'}

"I could mention other" cases, but these are sufficient for the present purpose. I must now direct your attention to the most injudicious parsimony that was ever introduced into any establishment. The crutches are purchased for the hospital at 2s. per pair; and as it was found that some of the patients, after being permitted to take them out, did not return them, the director ordered that all the patients going out with crutches should leave a deposit of a shilling.
Now, look at the effect of this. I will give it in a case : A poor man, a labourer, met with an accident in the course of his employ, and fractured his leg. He remained seven or eight weeks in the hospital. The union of the broken bones being perfect, I recommended him to return to his family. The sister of the ward asked 'What he was to do about the crutches?' I was ignorant of the order that had been given, and replied, 'Why, take them, to be sure; and, when he is able to get about without them, let them be brought back to the hospital for some other afflicted person.'-' Sir, Dr. Golding says that a shilling deposit must be left, and the poor man has it not.' He had not a shilling in the world. I paid the deposit, and bade the man not care about the crutches. Here is a poor creature, meeting with a serious injury that incapacitates him from supporting his family, stopped at the threshold of a charitable establishment for a shilling deposit for his crutches! What are likely to be the feelings of patients thus treated, and in what way are they likely to speak of the hospital? Then, as governors of an institution, what are you to say to this conduct? Is it not more economical to risk the return of the crutches, than for the man to remain a week or two longer, to be fed and supported at the expense of the establishment?

"It has occurred to me, during my connection with the hospital, to witness the wretched supply of the necessary instruments and bandages, and $I$ had an instance of an omnibus-driver (whose name I forget), who had a fracture of the thigh, kept, unnecessarily kept, in his ked at least ten days longer than he might have been, from the inability to obtain crutches for him. When a man has been confined to one position for seven or eight weeks, it is a dreadful cruelty to retain him one day beyond the time absolutely necessary for his recovery. Another man, with a fracture of the neck of the thigh-bone, was unable, for many days, to obtain the proper-sized crutches, and ventured to use a shorter pair than were adapted to his height. He fell, and was in consequence keet to his bed for some days from the shock he sustained. I have heard of a case of Mr. Howship, a child with a fractured thigh being dismissed the hospital with a very crooked limb from the want of splints. The want of these, of bandages, \&c., has veen truly distressingevery fracture that has to be adjusted is delayed by the necessity of making the proper pads, \&c., at the time. I was called upon only a few days ago to tap a patient of Dr. Shearman's, labouring under ovarian dropsy; and, upon asking for a flannel roller, there was not such a thing in the hospital! There are nothing but ordinary rollers, and those scanty in number-no eighteen-tailed bandage-no complicated bandages required for particular injuries; and will it be believed 
that to this day there is not a proper operating table! The operations are obliged to be performed upon a table by far too broad for the purpose, and one which is used at the lectures. There are no pullies for the reduction of dislocations, nor a bolt even placed for the use of them. I might enumerate many other things, but $I$ am sure these are suficient to show the management of the hospital, under the guidance of the director, has been very defective. Yet the funds are declared to be adequate, and the hospital to be 'free from debt and incumbrance of any kind.' Yet, if a patient is to be visited after dark, not a candle is to be had to examine him, but at the expense of the sister of the ward, the lights of the hospital being restricted to the jets of gas in the apartments. These are all matters which fall under the director's attention. It has been in vain to apply to him, and the special committee designate them (the complaints) ' frivolous;' the governors at large will, I flatter myself, entertain a different opinion.

"The complaints I have urged on this head, and a variety of others, have brought down upon me the animosity of the director and his two coadjutors, Mr. Robertson aud Dr. Shearman, and has given rise to a gross and false accusation, with the intention of inflicting a wound on my reputation, which I shall presently notice in a particular manner."”

Mr. Pettigrew then details the particulars of a proposal which was made " through Lord Henley, in a letter from the Bishop of London," to unite the Charing-Cross Hospilal and King's College. The terms demanded on the part of King's College, however, were not acceded'to, and the negociation dropped. Soon after this Mr. Pettigrew says that he received " the most ungracious and unjust treatment from Dr. Golding and some of his colleagues," (who alway's side with the " director"). He expressed " his dissatisfaction at the conduct shewn to him, and, in a letter to Dr. Golding, expressed his determination to promote an union between the college and the h 'spital, having first of all undertaken the disties of lecturer on anatomy and physiology at the hospital " to save the school from sinking." This attempt to effect the union, however, was disagreeable to Dr. Golding and his friends, and, accordingly, the special committee declared the proceeding to be "unfairly carried on, uncandid, and highly reprehensible," and it was thereupon unanimously resolved by the committee " that Mr. Pettigrew's services as a professional officer of the hospital should be forthwith dispensed with, and that he be no longer an officer thereof." A similar measure was adopted towards " his excellent friend and enlightened colleague Dr. Sigmond." This resolution was passed Angust 1st, by the member's of a special committee appointed by the board of governors. Mr
Pettigrew, however, wholly denies that any uncandid proceeding was adopted by him, and proves that Dr. Golding was made fully acquainted with his intention in the letter dated the 10th of February last.

Mr. Pettigrew then makes the following statement, which we abridge from the original :-

"But the matter, although placed upon this ground, is not to be considered as based solely upon it, for an attack has been made upon my character, which I hold dearer than life itself.

"During twelve years I was the sole surgeon of the institution, which was at that time a dispensary in Villiers-street; the duties were arduous, but I never derived one farthing of emolument for my services. When the institution assumed the character of an hospital, I suggested to my colleagues, Drs. Golding and Shearman, that it would be necessary for me to have some one with whom I might consult on the various operations necessary to be performed, and who would share the responsibility of such onerous duties. It was admitted; and Dr. Golding told me, in the presence of Dr. Shearman, that I should be permitted to name an acceptable and proper person with whom I should like to be associated, who would not be entitled to receive any part of the emoluments from the office for a period (five years were expressly named by $\mathrm{Dr}$. Golding, the director), as it was held to be unjust to place upon an equality any individual who might not have taken part in the establishment of the hospital, with one who had devoted so many years to its support. Upon this being known, Mr. Howship applied to me. We were then strangers, we did not visit each other, nor had I ever been in his house. He said he should be delighted to be connected with me in the Charing-Cross Hospital, and that he should consider any assistance rendered him in attaining this object as the greatest of obligations, and never forget it. He urged the particular advantage of his preparations, foolishly eulogizing them as exceeding in value those of St. George's Hospital, and put forward other reasons to induce me to favour him as a colleague. Duly considering the matter, and with a firm determination to do my duty to the hospital, I weighed well Mr. H.'s pretensions. I regarded him as a qualified individual of even longer standing in the profession than myself, a member of the council of the Royal College of Surgeons, the author of some works on surgery, one in the habit of lecturing, furnished with preparations to illustrate a course of lectures on surgery, and, above all, living contiguous to myself, and therefore readily to be $o b$ tained to supply my place if absent in any case of emergency that should arise. These advantages outweighed those suggested to me by many others who proposed to me on 
the same matter; and I therefore stated the offer made to me of naming a person who should be acceptable to my colleagues, and their conviction that I was entitled to receive the whole of the emoluments derivable from my department for five years; but $I$ proposed to $\mathrm{Mr}$. Howship, as a private arrangement between two gentlemen, that instead of my receiving the entire emoluments, he should be entitled to an equal portion, upon the consideration of his paying to me, in lieu of those emoluments, the sum of $£ 500$. Now, this has been made the subject of a charge of having sold my influence to secure the election of $\mathrm{Mr}$. H. to the office of visiting-surgeon to the hospital. I did no such thing. It is merely a composition for the amount of fees that may be received; and, taking into consideration the length of time in which it was proposed I should receive the fees, and the probable amount of them from the progress of the hospital (under judicious management), it must be admitted to be a very small sum for such advantages. The grounds upon which $I$ made this proposal, and which were communicated in writing to $\mathrm{Mr}$. Howship, and marked private, were these : that the duties of the hospital were more likely to be cheerfully and amicably performed by a perfect equality of the officers; that however just it might be felt by my colleague to refrain from receiving any fees for the time specified, yet that to toil on year after year, in the performance of duties, the return for which would be continually appropriated to another's benefit, was likely to lead to a laxity of atten tion and a diminution of zeal; that by an equality being established, each surgical officer would be entitled to lecture on their branch of the profession, and thus to divide the emoluments derivable from their class, and that the pupils might have the advantage of two instructors in the same branch. This was an arrangement strictly private in its nature, and in no way interfering with the objects of the hospital, or any rules of the governors. That Mr. Howship did not ever consider the transaction unjustifiable is proved by the following fact: that, shortly after being appointed visiting-surgeon, he asked me to promise him my influence in support of his pupil, Mr. Turuer, to become assistant-surgeon when an opportunity presented. I replied that I could make no promise, but that it would certainly give me pleasure to do any thing that might prove agreeable to my colleague. He then added, if that were effected, he should be able to obtain a portion of the amount he had paid to me. This person ( $\mathbf{M r}$. Howship) now presumes to state that he is not prepared to maintain that such a transaction is justifiable as a general principle; and I therefore leave the governors and subscribers to form an esrimate of his veracity. At this time he regularly brought Mr. Turner with him to the hospital, and that gentleman can be exaamined to prove that Mr. H. has been in the habit of proposing to him a variety of things for pecuniary consideration, and even a partnership in his own professional engagements, and a joint property in his museum. Mr. Howship chooses to say that he has been ' misled.' He has indeed, but not by me. Hie is the willing tool of designing men to endeavour to blast the character of one who is obnoxious to them, from his determination to resist tyranny, and see the charitable objects of the institution camied into effect. Considering the whole of Mr. H.'s conduct in the business, I would apply to him a remarkable passage in the works of one of the ablest English writers, addressed to a 6 certain esquire :' 'You are wholly out of danger: the weapons I use will do you no hurt; and to that which would keep nicer men in awe you are insensible. A needle against a stone wall can make no impression. Your faculty lies in making bargains: stick to that.'

"But, to return to the arrangement, I contend that it is simply a composition, and nothing else; and I desired the director to pay over to Mr. H. an equal portion with myself, which has been done from the moment of Mr. H.'s counection with the hospital. Mr. H. says he was principally governed by the desire of being surgeon to an institution which he had reason to believe would one day become one of the most distinguished hospitals of the metropolis. What his desire was does not signify. What he paid the money for is the point ; clearly for the receipt of half the fees from the admission of pupils to the hospit 1 l and the lectures ; for, without my concurrence, Mr. $\mathrm{H}$. being only the visiting surgeon, could not have delivered any part of the surgical lectures. The duty of teaching thut branch was vested exclusively in me. That he was actuated by this consideration is also apparent from his stating to me a sum of money paid at another hospital, and drawing his inferences as to the respective value. He wished to reduce the amount to $\$ 300$, and I reclined the proposal, regarding the probable amount of fees, \&c., to be received during five years, as being in value far exceeding that sum. This was the cause of the negociation (as he called it, to Dr. Shearman) being bioken off; and he, not $I$, renewed the subject in 1834, and expressed his willingness to accede to my former proposition. It would have been more advantageous for me to have received the whole of the fees for the five years; but a variety of circumstances of a private nature rendered the receipt of $£ 500$ to me at that moment a matter of personal convenience. I did not disguise this from the director. He told the special committee that he received a letter from me alluding to the same, and that he suspected there was a transaction of the kind going on. He says he communicated the same 
(though conveyed to him privately) to Dr. Shearman and to Mr. Robertson. None of these gentlemen said one word to me on the subject. Although I had laboured with them for years, and with great assiduity, they none of them ever said a word to me about it. If they held it wrong, surely they should have noticed and prevented it; and I am sure that the explanation I have now given would have then satisfied them, whatever may be the case now.*

"Notwithstanding the present serious charge, the laws of the hospital recognize pecuniary transactions in this respect; for it is expressly stated that, in the event of any teacher resigning or dying whilst a teacher at the Medical School, he is entitled to receive, if resigning, from his successor, a sum equivalent to the clear receipts resulting from his exertions during the twelve months immediatety preceding his resignation; and, if dying, his widow or administrator to a like sum; and if not demanded by either, then the secretary can claim it after the lapse of three years for the funds of the charity.

"I now confidently submit this subject to the consideration of the governors and subscribers at large, and I trust that they will not fail to look back and review my character previous to and during the period I have been connected with their institution. Every thing that I could do to promote the welfare of the hospital I have done, and my family have lent their exertions, and I have supported the Medical School far beyond all my colleagues, by my collection of preparations, without which it could not have gone on. And here allow me to contrast my conduct with that of Mr. Howship, and this will also explain how the charge against me of having sold the apointment came to be brought forward. When the preparations were to be arranged in the Museum, I found that Mr. H. had ordered particular locks to be put upon the cases in which his were to be contained. I had, in common with my colleagues, conceived that the whole were to be arranged in an order calculated to give instruction to the pupils, and that they would be used in common by all the teachers of the School. I objected to Mr. H.'s preparations being placed in the Museum, unless agreeably to this feeling; and he, determining on a selfish appropriaton, declined to do so, or to permit any body to use them but himself, or at his special loan-a condition that no gentleman could submit to-notwithstanding I had admitted him to half the surgical course. He complained to Dr. Golding upon the subject of my remonstrance, and

* Dr. Sigmond heard of the transaction, and mentioned it at the time to Dr. Golding; but that gentleman and Dr. Shearman have the most convenient memories for things they choose to recollect, but no further. said he did not consider he was bound to this when he gave me the $\$ 500$. But I need not say any thing further respecting $\mathrm{Mr}$. H.

"Having thus disposed of the charge preferred against me, I must direct attention to the manner in which the subjects under consideration have been proceeded with. That personal feelings instigated the enquiry I have alluded to, is evident from a variety of circumstances."

Mr. Pettigrew here adduces some evidence to show that Dr. Golding knew that he was making a "negociation" with Mr. Howship, and that its consummation would be a "personal convenience" to Mr. Pettigrew. "Could Dr. Golding," he says, "imagine it likely that I should labour for twelve years to form the Institution, during which time it was incapable of yielding any emolument, and that when the prospect of a tolerable addition to my income was created, I should so entirely forget what was due to my own interests and to the support of my large family, which Dr. G. knew rested entirely upon my own professional exertions, as to voluntarily forego one half of the amount, without receiving any equivalent? Ds. G. is too close in all his pecuniary transactions, to have given any one credit for so much generosity. Dr. Golding says that hewrote to Dr. Shearman, in May 1835, upon hearing from MIr. H. that he had given to me $£ 500$. This was after dissentions had arisen with respect to the management of the Medical School, and then put for the teachers to say whether it was justifiable in any officer to barter away the appointments of the hospital. This was an attempt to take an unfair advantage, to be afterwards used for some wicked purpose, although I could not suspect that any one could be guilty of so base a breach of confidence as to communicate such a transaction as having really taken place. I urged that if there was any ground to suspect such a case, the fair and manly way was to take it before the governors at large. This was, however, deelined; and, will it be believed, that $\boldsymbol{M r}$. Howship either proposed or seconded (I do not know positively which) à resolution to declare that such a proceeding was improper and unjustifiable? From this time I refused to attend any more meetings of the Meaical Committee until the offensive resolution was expunged. Well, there it stands now ; but remark the distance of time that was permitted to elapse by Dr. Golding before this matter was taken into consideration,-six months. It was my intention to bring it myself before the governors. I told my colleagues I should. I applied to the secretary to get a meeting."

But this, Mr. Pettigrew says, he was, by an intrigue, prevented from getting; and that at a time when it was most unfair to himself and Dr. Sigmond, a meeting was held, and he and his colleague removed from their 
offices. He then proceeds to show what were the occupations and connections of the committee who served Dr. Golding's purpose at meetings for these expulsions. It consisted of ten persons, whom he describes as follows :-

A clergyman, an " honorary governor," made at the suggestion of Dr. Golding, or Mr. Robertson, not a contributor to the funds of the institution.-Another clergyman, a "Life supporter only, and not admissible therefore to the committees."-The druggist to the hospital, " an intimate of Dr. Golding."-Another " honorary governor."-An " old supporter of the institution." (The two last were not present at the votes of expulsion).-An " apothecary in Westminster, an old intimate of Dr. Golding." - A currier, " another intimate and a patient of Dr. Golding."-The "dentist to the institution."-A "life governor" of a month's standing, an amateur musician.The brother-in-law of Dr. Golding.

"It cannot," says Mr. Pettigrew, " be matter of astonishment that any decision to which a committee thus constituted has arrived, should be protested against ; and I hereby do solemnly protest against this gross tyranny and usurpation, worthy only of the most despotic times. The dismissal of any officer I contend must of necessity rest with the governors at large, the elective body. The present proceeding is too gross and monstrous. And I therefore call upon the governors and the subscribers, for they, too, mast raise their voices to assist me in unmasking this infamous job, and placing the charity upon the only true and honest basis on which it can stand, if it is to do justice to the intentions of its supporters and the demands of the public. I will incessantly labour until this be accomplished, and $I$ beg, therefore, of all who read this address to forward to me their names, if they feel disposed to co-operate in any way with me. We can bring a host of credible witnesses to prove a mismanagement far beyond what it is possible to conceive. The want of bandages, splints, tourniquets, and other instruments, I have already noticed. The appointment of servants is not less to be censured. There is at this time a cook who does not understand the dressing of meat, and who was brought into the hospital for a cut throat, inflicted by herself. We have had drunken nurses, and an epileptic patient was even made a nurse. In short, in every department abundant matter for correction presents itself.

"I trust $I$ have successfully vindicated my own character, and that I may safely defy the machinations of artful and wicked men, who have attempted to promote their own base and tyrannical views. I rely with the greatest confidence on the opinion which shall be formed by the subscribers, and the members of my own profession, upon the perusal of this hastily written address, which has been hurried to a degree quite painful to my feelings, but I could not lose a moment in endeavouring to remove any imputation that might be supposed to rest upon my character.

\section{"Saville-row, August}

ville-row, August 22d, 1836.

"P.S.-I deem it needless to notice the various personal annoyances to which $I$ have been subjected, or the means resorted to, to check my desire to comply with the regulations of the Royal College of Surgeons. There has never been any thing like the complement of patients required, since the recognition of the hospital (by the College) was obtained."

\section{INTERCEPTED LETTERS.}

"My Dear Fellow :-Pray look at this letter and tell me if it be not the very thing. In fact, I feel remarkably sure of the chair. Don't think me inconsistent in the praise of the demi-Tory demi-Liberal, because I have at all other times $\mathrm{d} \longrightarrow \mathrm{d}$ him up hill and down dale. I am well assured that he is the Alpha and Omega of the electoral body, and that nothing is to be done there without holding a candle to his majesty. No doubt he has got his little job to accomplish, which it is my policy, by a little flummery, to induce him to abandon. If you approve of the letter, I will send it without altering a word. You may laugh at the account of my elocution, but as I have not lately had any pupils to give me a "certificate" on that point, I don't see that a better testimonial to my oratorical powers, than my own, can be furnished. Surely I ought to know them, who have so often heard the echo of my own voice in the lecture-rooms. Besides, I have stated at the end of the letter, that "what I ' have said of myself must not be imputed ' to over-weening self-esteem, but to my ' strong auxiety to state what I think I pos' sess in the way of qualifications for the ' chair,'-an important distinction, as you will admit.

"As for King's College, I have satisfactorily ascertained that, should $I$ fail at the University, and wish to return to the old place, the generous-hearted baronet will propose the recal of my resignation, and that Sir Benjamin will second the motion, of course successfully. Believe me, ever yours,

"Greorge-street, July 30, 1836."

"H. M.

The Letter.

"SIR :-In offering myself as a Candidate for the vacant Professorship of Anatomy in the University of London, I may be permitted 